\title{
Research on Logistics Problems and Countermeasures in Chinese Cross-border E-commerce Development
}

\author{
Lihua Liu \\ Jingzhou Institute of Technology, Jingzhou 434020, China
}

Keywords: Cross-border e-commerce; Logistics management; Countermeasure research

\begin{abstract}
The cross-border e-commerce has gradually become China's main way and channel to exploit international economic market, and it can effectively realize the transformation of Chinese economy and trade. In recent years, although there is only short time for China's construction of cross-border e-commerce, the certain achievements and scale have been achieved, which brings an economic market to logistic development. However, due to rapid development, there exist some problems in development process, thus we shall continuously enhance logistic management on cross-border e-commerce, improve the efficiency of logistic operation and reduce the cost so as to promote e-commerce development to maximum degree.
\end{abstract}

\section{Introduction}

With continuous development of social economy, the cross-border e-commerce has become China's main way to exploit the market, and also an important means to promote the trade growth. The logistics is an important part of e-commerce and the main bridge to connect buyers and sellers. The foreign developed countries have started to carry out cross-border e-commerce logistics management at an early time; although China starts this management lately, it also has obtained certain achievements; meanwhile, some problems also exist, which restricts the development of Chinese cross-border e-commerce to a great degree. Therefore, it is necessary to carry out analysis on problems related to logistics management in Chinese cross-border e-commerce for the purpose of proposing some constructive solutions.

\section{Logistics service requirements in Chinese cross-border e-commerce development}

In recent years, the development speed of Chinese traditional foreign trade slows down, but the cross-border e-commerce still keeps rapid growth. The cross-border e-commerce trade has become more and more normalized. The logistics is a necessary important link in e-commerce activity process, and the logistics service environment directly influences the development of e-commerce. The e-commerce and logistics service supplement each other, and this is especially obvious in cross-border e-commerce.

Firstly, the logistics can effectively realize e-commerce. The logistics can promote the production. As for both e-commerce and traditional way, the logistics is main way for commodity circulation; therefore, the overall production process is actually a series of logistics activities, and it is able to effectively reduce cost, continuously optimize the structure, shorten the period, and reduce capital occupying through logistics so as to promote production efficiency to certain degree. Secondly, the logistics can serve for commerce very well. In the e-commerce process, after the goods ownership contract is signed, only both parties' rights are moved, and the goods are not moved or changed. Through the e-commerce, the customers can surf the internet to purchase the goods they need and then complete the hand-over of goods property; this is actually the circulation of goods. However, at this time, the e-commerce activity is not truly completed; only after the goods arrive at the purchaser's hands, it means that the activity has been truly completed. Thirdly, the development of e-commerce improves the complexity of logistics. Due to continuous development of commerce, all industries hope that the goods can be delivered to customers on time and hope to realize multiple-batch, small-amount, and quick-speed logistics service mode as much as possible. With 
continuous development of e-commerce, this small-amount service mode gradually adds the operation difficulty of logistics. At current stage, this kind of multiple-variety and small-amount way gradually replaces large-volume production, thus the higher requirement is proposed for storage, delivery, and circulation of logistics.

Driven by cross-border e-commerce, the quantity of Chinese cross-border packages also keeps rapid growth in recent years, and $70 \%-80 \%$ of cross-border express mails are realized via e-commerce. The international logistics \& express companies such as FedEx, UPS, DHL, and TNT are main carriers of cross-border packages. Except for express companies, the international shipping companies such as MSK are also available. Although Chinese enterprises such as China Post and SF-express also start to expand the service project of cross-border logistics and delivery, there still exists large gap in terms of international coverage, logistics distribution efficiency, and collection of logistics information compared to international logistics \& express companies, thus it is hard for them to meet the demand of e-commerce enterprises. The construction and perfection of logistics service system is still the main challenge that China shall face in the development process of cross-border e-commerce.

\section{Logistics problems faced in Chinese cross-border e-commerce development}

\section{No perfect support of logistics policies}

Currently, although Chinese cross-border e-commerce starts lately, its development speed is very quick; for example, Alibaba is the most representative enterprise. Despite of no support of policies at current stage, the cross-border e-commerce will attract more and more attention due to the fact that it is a new direction of promoting economic development. The notice related to cross-border e-commerce have been issued in 2013, and it proposes the solutions for problems met in customs inspection and customs revenue of products. The launching of this policy brings the chance for development of many retail enterprises. Besides, China shall continuously establish the standard of basic information. At current stage, only small part of enterprises can realize connection with e-commerce to promote the information exchange between logistics and enterprises. However, compared to cross-border e-commerce in developed countries, Chinese policy support is still not enough, which hinders the development of logistics enterprises and e-commerce to a great degree.

\section{Mismatching between actual demand of cross-border e-commerce and development speed of international logistics}

Due to continuous social development, Chinese cross-border e-commerce has a rapid development speed. The total trading volume in 2012 is 2,000 billion, and the total trading volume in 2014 is up to 3,750 billion, thus it can be seen that the scale is continuously expanded. However, only few logistics enterprises are corresponding to e-commerce, and also few logistics enterprises engage in cross-border commerce which is generally completed by the logistics of international companies. However, as for so large volume of logistics, it can't be completed well only by virtue of international express; in particular, in busy season, the full warehouse and overstock can easily appear, which hinders the development of cross-border e-commerce to certain degree.

\section{No perfect logistics infrastructure}

The logistics starts lately in China, and the overall level is not high; furthermore, there are only few hubs which can connect the transportation and circulation, and no perfect infrastructure. The cross-border e-commerce often meets the problems such as distribution, transportation, storage, tax checking, and customs declaration. In order to reduce the loss to maximum degree, continuously reduce the cost and improve speed, it is required to establish certain logistics system and perfect the construction of infrastructure. However, at current stage, the problems such as various logistics transportation procedure, long time, and high cost in China cause slow development of cross-border e-commerce logistics.

\section{No third-party logistics professional service}

Currently, there are many third-party logistics in Chinese e-commerce, but only few professional and large-scale third-party logistics; the common logistics services are basically domestic logistics, 
and the e-commerce that the logistics serves for is also domestic e-commerce. The international express is basically common expression, and no professional, and comprehensive logistics service companies are formed. At current stage, the domestic cross-border e-commerce logistics mainly includes: FedEx, China Post Express, DHL, and UPS. Therefore, it is very important to establish professional logistics service companies, which is of great significance for domestic cross-border e-commerce development.

\section{Solutions for logistics problems in Chinese cross-border e-commerce development}

\section{To establish perfect legal system for cross-border commercial logistics}

The cross-border e-commerce is actually a kind of emerging industry, and there is no perfect legal system at present. Through establishing good and comprehensive legal environment, it is able to develop cross-border e-commerce well, and also improve the operation efficiency to certain degree. At current stage, there are no perfect customs clearance procedure, standard process, storage management and relevant legal mechanism of cross-border e-commerce. However, due to continuous progress of e-commerce, as a necessary part of cross-border e-commerce development, the laws and regulations can play certain function on customers and cross-border e-commerce enterprises, and promote healthy and rapid development of cross-border e-commerce. Furthermore, at current stage, there is no perfect government support, thus the relevant department shall propose new policy as much as possible, and continuously carry out procedure simplifying and financial support to promote the development of cross-border e-commerce. The Opinions on Implementing Relevant Policies of Supporting Cross-Border E-commerce Retail Export proposed in 2013 stipulates to gradually include the retail into customs export trade, and also proposes support policy, collection and settlement of exchange, and export inspection measures; however, those policies are still not enough, and it is still required to carry out policy development to maximum degree.

\section{To establish professional third-party logistics enterprises}

Through third-party logistics enterprises, it is able to establish professional logistics service and provide customers with high-quality and overall logistics service. Currently, there commonly exist third-party logistics companies in China, but there is no professional third-party logistics company which can provide logistics service for cross-border e-commerce enterprises. The main reason why the cross-border e-commerce is different from domestic e-commerce is that it has the feature of cross-border transaction, and the logistics operation and transaction process are more complicated; in the whole process, many aspects will be involved, such as customs inspection and international transportation, thus a great influence is caused on the development of cross-border e-commerce. However, if the professional third-party service mechanism can be established, it is able to effectively improve efficiency, reduce the cost, and meet customers' actual demand.

\section{To establish overseas storage}

The overseas storage is actually established based on actual demand of cross-border e-commerce, and it generally includes two modes, that is, outsourcing and self-support. At current stage, the main logistics operation way of cross-border e-commerce is outsourcing storage; through use of overseas storage, it is able to provide enterprises with overseas service well, and promote smooth completion of distribution of goods. From perspective of cost, this way is the way which most suits the demand of cross-border e-commerce. However, as for enterprises, they not only need to consider the cost, but also need to fully consider customers' actual demand, customers' satisfaction, goods management, market opportunity, and inventory control, and they can also suitably use the self-support overseas storage whose main advantages include reduction of inventory, high satisfaction and large market effect. As for B2C and B2B, the self-support is the best logistics operation way.

\section{To establish the strategic alliance of cross-border e-commerce enterprises}

From perspective of cross-border e-commerce enterprises, the independent logistics operation will add the cost to certain degree; from perspective of economic benefit and scale, the cross-border e-commerce enterprises can carry out continuous cooperation to perfect the strategic alliance. Those enterprises can unite together to establish a storage center at home and abroad, and the cooperating 
enterprises can transport their goods to the storage center established by the alliance for storage; while the customers book an order and make payment, they can carry out overseas distribution according to purchase address and relevant information, and then deliver to the customers by use of overseas center.

\section{To innovate the operation mode of cross-border e-commerce}

The main operation modes of cross-border e-commerce include C2C, B2B, and B2C. B2C mainly refers to a kind of consumption mode that the enterprises directly affect and face customers. The main enterprises include JD, and Tmall, etc. which carry out operation via independent management, platform construction, and self-production and marketing; such mode can adapt to domestic e-commerce, but it is not applicable to cross-border e-commerce. C2C mainly refers to the transaction mode between individuals, and it is generally applicable to small dealers; the most representative platform is Taobao. Such mode is generally featured by small batch, directness, and large volume, and it is not applicable to cross-border e-commerce. B2B is actually the transaction between enterprises; under this e-commerce mode, the enterprises can carry out connection between goods information and suppliers through information platform and then complete the payment and order-booking; however, this mode is not suitable in international market and has weak operability.

Based on above analysis, it can be seen that the above three modes are not suitable for cross-border e-commerce; through combination with the features of cross-border e-commerce, it is able to establish a platform-to-platform operation mode, that is, to realize the e-commerce via reasonable connection between overseas platform and domestic platform. The basic operation procedure is shown as below: firstly, the domestic customers can release the information about products they want to sell; secondly, there is a reasonable conversion between domestic and overseas commerce platform; thirdly, the information is reasonably released on overseas e-commerce platform according to the features of their county; fourthly, the purchasers can complete order-booking and payment operation by use of their domestic platform; fifthly, after receiving the information, the domestic e-commerce platform carries out corresponding classification and summary and then sends to overseas platform to complete the payment operation; sixthly, the platform contacts with the enterprise and delivers the corresponding orders to corresponding enterprise which then purchases the required goods; seventhly, the products are delivered from overseas to domestic; eighthly, the domestic platform classifies the goods information and then delivers the goods to customers. This platform-to-platform mode not only can reduce the cost in logistics transportation, but also can improve transportation efficiency and reduce the demand of cross-border logistics distribution service.

\section{Conclusion}

In conclusion, the cross-border e-commerce gradually becomes an important means and way to promote the development of logistics industry, and also the hot point of future development; furthermore, as the time goes by, the stricter requirement will be proposed for logistics, platform, and customers inspection, thus the relevant department shall pay high attention. In order to realize better development of cross-border e-commerce, it is required to establish automated, information-based, network-based, and modernized logistics system, increase the construction of logistics infrastructure and management system, and promote rapid and healthy development of logistics industry so as to realize the modernized construction of e-commerce in a comprehensive way.

\section{References}

[1] Tao Lili, Logistics Management Mode Based on E-commerce Environment, Market Modernization, 2013 (27).

[2] Li Lingchuang, Research on Centralized Management Mode of Anhui Tobacco Commerce Logistics under E-commerce Environment, Anhui University, 2011. 
[3] Fang Yue, Modern Logistics Management and Construction of Tianjin Logistics System, Tianjin University, 2010.

[4] Shao Zhenwen, Research on Web-based Enterprises Sales Logistics Management Remote Operation Platform, Sichuan University, 2011.

[5] Tang Dan, Research on WEB-based New Generation of ERP Logistics Management System, Huazhong University of Science and Technology, 2011. 